Revista Destaques Acadêmicos, Lajeado, v. 9, n. 4, 2017. ISSN 2176-3070 DOI: http://dx.doi.org/10.22410/issn.2176-3070.v9i4a2017.1653 www.univates.br/revistas

\title{
APLICAÇÃO DA VERMICOMPOSTAGEM NO RESÍDUO TRATADO DE INDÚSTRIA DE CURTUME PARA CULTIVO DE RÚCULAS
}

\author{
Lucélia Hoehne, Franciele Raquel Schmalz, Elisete Maria de Freitas, Daniel \\ Kuhn, Henrique Pretto Etgeton, Wagner Manica Carlesso, Maria Cristina \\ Dallazen, Carla Roberta Orlandi, Fernanda Bruxel, Rafael Pinto dos Santos, \\ Aluisie Picolotto, Cristiano Giovanella, Eduardo Miranda Ethur
}

Resumo: A preservação do meio ambiente desperta a procura por alternativas que minimizem o impacto ambiental causado pelo processo produtivo em curtumes. O lodo gerado nos curtumes possui em sua composição o metal tóxico cromo (Cr). Este resíduo pode ser tratado por diferentes processos químicos, físicos e biológicos. Uma alternativa para aproveitar os resíduos orgânicos é a vermicompostagem, que utiliza minhocas para acelerar a decomposição destes resíduos. Este trabalho teve o objetivo de avaliar o reaproveitamento do resíduo tratado de indústria de curtume na produção de húmus por meio do processo de vermicompostagem e sua posterior utilização como fertilizante no cultivo de rúcula. Para isso, foram realizados testes com diferentes proporções de resíduo tratado de curtume com solo para posterior montagem dos minhocários e aplicação da vermicompostagem. Após definição da melhor condição, foram incubadas 15 minhocas da espécie Eisenia andrei em recipientes padronizados. O húmus gerado foi caracterizado e utilizado para o plantio de rúcula em nove tratamentos com diferentes proporções de húmus:solo e de branco:solo (0:100, 25:75, 50:50, 75:25 e 100:0). Depois do crescimento, as rúculas foram coletadas e submetidas às análises de massa seca, massa fresca, altura total, comprimento da raiz e número de folhas. Como resultados, o húmus produzido apresentou altas concentrações de N, $\mathrm{P}$ e K e a concentração de $\mathrm{Cr}$ foi reduzida de $128 \mathrm{mg} \cdot \mathrm{kg}^{-1}$ para $96 \mathrm{mg} \cdot \mathrm{kg}^{-1}$. Não houve diferença estatística nos resultados para o crescimento das rúculas usando a condição 25:75 de húmus e de solo, em relação ao teste sem resíduo de curtume.

Palavras-chave: Minhocas. Efluente de curtume. Cromo. Biofertilizante.

\section{INTRODUÇÃO}

Para cada segmento de indústria existe uma legislação vigente que estabelece padrões de lançamento de efluentes líquidos. Os efluentes de indústria de curtume são constituídos de alto teor de matéria orgânica e inorgânica, sendo importante a implantação de tratamentos adequados nas 
estações de efluentes. Com isso, as indústrias vêm adotando tecnologias alternativas para atenuar as cargas poluidoras geradas no processo industrial e pesquisando formas de reutilizar o resíduo tratado em solos agrícolas de modo a evitar danos ou riscos à saúde e à segurança e de minimizar os impactos ambientais.

O lodo de curtume é definido como resíduo do procedimento industrial das peles de animais. Apresenta elevado potencial poluente pela presença de metais tóxicos como o Cromo $(\mathrm{Cr})$. Dessa forma, vem a necessidade do manuseio correto para evitar contaminação ambiental (KRAY, 2001).

No Rio Grande do Sul, a Resolução do Conselho Estadual do Meio Ambiente (CONSEMA) n 128/2006 obriga os curtumes a tratar suas águas residuais. Já a Resolução do Conselho Nacional do Meio Ambiente (CONAMA) $\mathrm{n}^{\mathrm{o}} 357 / 2005$ cita que somente poderão ser lançados efluentes nos corpos receptores, após o seu devido tratamento (CONSEMA, 2006; CONAMA, 2005).

Esse tipo de resíduo pode conter diferentes concentrações de elementos químicos ou demais substâncias que podem trazer efeitos negativos sobre a qualidade do solo e o crescimento das plantas quando colocados em locais inapropriados, quantidades inadequadas ou até mesmo sem nenhum tratamento (ARAÚJO, 2009).

Desta forma, para o uso em solo agrícola de resíduo de curtume, é necessário avaliar o grau de estabilidade, composição química, principalmente a composição de metais, uma vez que esses elementos não são biodegradáveis e podem ser tóxicos em algumas concentrações e ou estados de oxidação, como por exemplo, o cromo (HAROUN, 2009; KONRAD; CASTILHOS, 2002; FERREIRA et al., 2009; ARAÚJO, 2009).

As finalidades do tratamento de efluentes líquidos são a destruição de micro-organismos patogênicos, a diminuição do número total de bactérias, a transformação de substâncias orgânicas em inorgânicas estáveis e inócuas, evitando desprendimento de substâncias mal cheirosas, a eliminação de sólidos resistentes à decomposição e a redução e modificação da natureza da carga poluidora (TEGNER, 2004).

Os efluentes de curtume são uma mistura de diversos tipos de resíduos líquidos gerados individualmente em cada etapa do processo de curtimento (CLASS; MAIA, 1994). Seus principais contaminantes são Cr, amônia, sulfatos, compostos orgânicos de baixa biodegrabilidade e o sulfeto (CAMPOS, 1999). Outras características estão relacionadas com o elevado $\mathrm{pH}$, alto teor de sólidos em suspensão (pelos, graxa, fibras e sujeira), coloração leitosa devido à presença de cal (óxido de cálcio), verde ou azul devido aos corantes de tingimento e elevada salinidade.

$\mathrm{O}$ cromo $(\mathrm{Cr})$ é um elemento químico classificado como metal e sua obtenção ocorre através do minério cromita, metal de cor cinza que reage com ácidos clorídrico e sulfúrico (CASTILHOS, 2001). O Cr pode apresentar vários 
estados de oxidação, desde a valência de $-2 \mathrm{a}+6$. As valências +3 e +6 são as mais encontradas no ambiente. $\mathrm{O}$ estado trivalente é a forma mais comum, mais estável, menos tóxica e de baixa mobilidade no solo, e pode estar na forma precipitada quando ligado a óxidos e hidróxidos em $\mathrm{pH}$ superior a 5,0. A forma hexavalente é mais instável, tem maior solubilidade em uma ampla faixa de $\mathrm{pH}$ e possui maior grau de toxidez (ALCÂNTARA; CAMARGO, 2001).

Compostagem é um processo de decomposição biológica da fração orgânica biodegradável dos resíduos, produzido por uma população diversificada de organismos, em condições controladas de aerobiose e demais parâmetros, desenvolvido em duas etapas distintas: uma de degradação ativa e outra de maturação, segunda a Norma Brasileira de Resíduos (NBR 13591, 1996). A compostagem é um produto estável e similar ao húmus e tem a vermicompostagem como processo posterior para acelerar a compostagem (SCHIRMER, 2010).

A vermicompostagem é um processo que utiliza minhocas para digerir matéria orgânica e acelerar o processo de degradação dos compostos. Esses vermes ingerem materiais orgânicos no processo de decomposição e excretam matéria orgânica humidificada, adiantam e apressam o ciclo do carbono (GARG; YADAY, 2011). É atualmente uma alternativa de tratamento de resíduos industriais que enriquecem o composto orgânico e promovem a redução de metais pesados presentes nestes resíduos para que não fiquem disponíveis no solo para a absorção pelas raízes das plantas.

Para um melhor processo de vermicompostagem são necessários alguns fatores, como fonte de alimento das minhocas pouco ácidas e sem cheiro forte, fazer a reposição destas matérias orgânicas de uma a duas vezes por semana, bem como temperatura e umidade adequadas (MARCONDES, 1996).

Devido ao lodo de curtume ser um resíduo de alto teor de carga orgânica, alguns estudos já foram realizados para aplicação como fertilizantes em solos. Um trabalho desenvolvido sobre o lodo de curtume foi avaliar as atividades microbianas em laboratório para verificar a redução do cromo hexavalente para trivalente, mostrando assim, que a atividade microbiana aumentou conforme os compostos do lodo, contribuindo para a redução do metal (CASTILHOS; VIDOR; TEDESCO, 1999; CASTILHOS et al., 2000).

Outro trabalho desenvolvido foi o uso da vermicompostagem para redução de cromo em lodo de curtume e posterior aplicação como fertilizante em plantação de cebolinha. Stevens (2014) estabeleceram tratamentos com diferentes concentrações do húmus obtido da vermicompostagem do lodo de curtume para germinação de mudas de cebolinha. Neste estudo verificou-se a redução de $\mathrm{Cr}$, ficando dentro dos teores permitidos pela legislação para áreas agrícolas.

Não foi encontrado nenhum trabalho com aplicação de húmus obtido da vermicompostagem do lodo de curtume em plantação de rúcula. 
Sendo assim, este projeto foi desenvolvido com o objetivo de verificar a possibilidade de aproveitar o resíduo de curtume como biofertilizante e avaliar a biodisponibilidade de $\mathrm{Cr}$ após o processo de vermicompostagem.

\section{PROCEDIMENTOS METODOLÓGICOS}

\subsection{Origem do resíduo}

Este trabalho foi desenvolvido com o efluente do reator biológico da Estação de Tratamento de Efluentes (ETE) do curtume Couros Bom Retiro Ltda, de Teutônia/RS (etapa 7 da Figura 1). O curtume em estudo processa o couro a partir do recurtimento, tingimento, engraxe e pré-acabamento. A Figura 1 indica o fluxograma da estação de tratamento da indústria.

Figura 1 - Fluxograma da estação de tratamento de efluentes do curtume

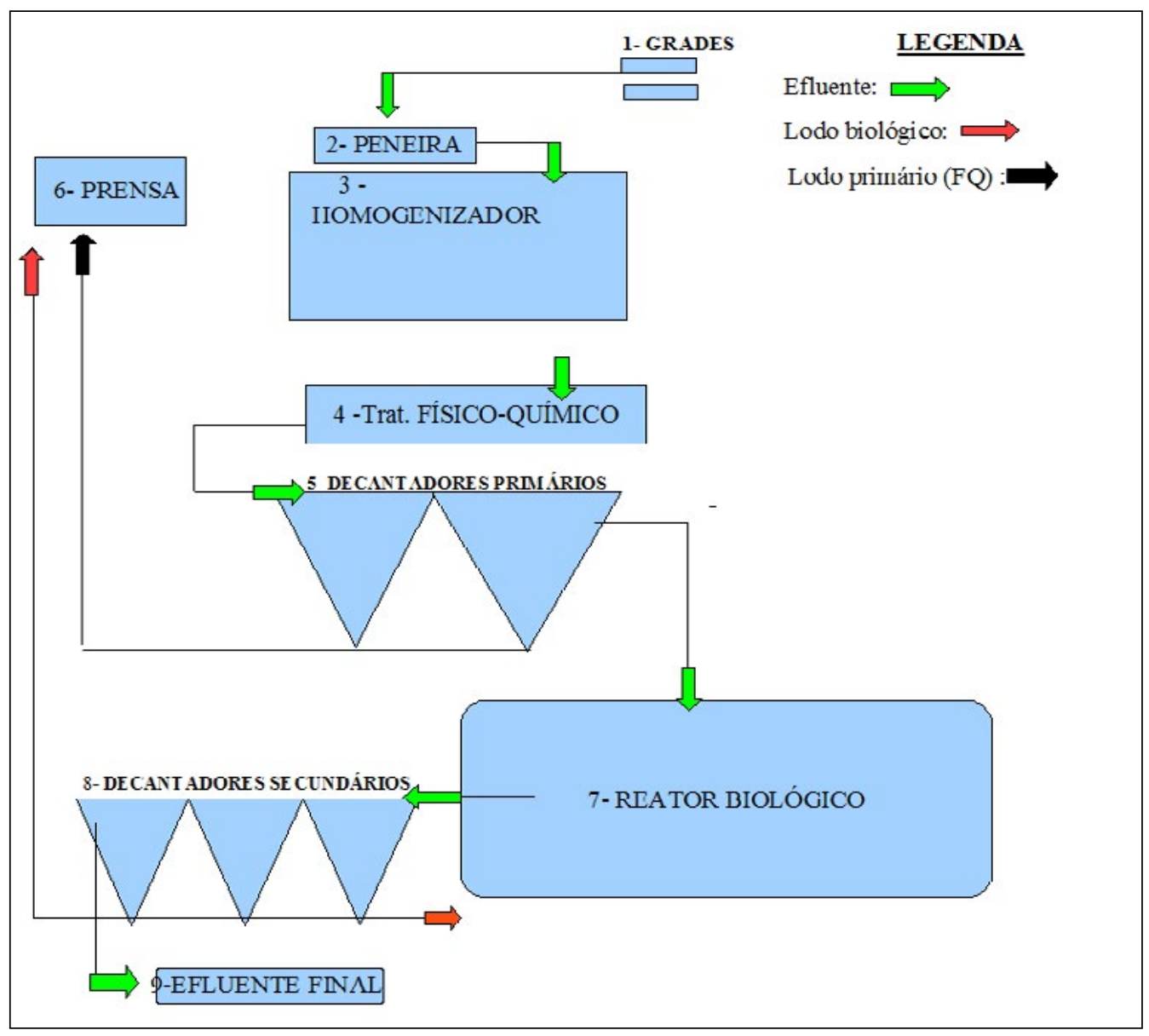

Fonte: Dos autores. 


\subsection{Secagem do resíduo e preparo dos substratos}

Para os substratos, foram coletados 20 L de resíduo sólido, mantidos em repouso por um dia para decantação, quando foi realizada novamente a filtração, secagem em estufa e trituração. O solo, utilizado para a condução do experimento, representa um solo típico da região do Vale do Taquari (argissolo). A Figura 2 evidencia os aspectos do lodo filtrado (A) e do solo usado inicialmente (B).

O solo e o resíduo triturado e seco foram misturados em diferentes proporções. A mistura então foi submetida ao teste de fuga das minhocas.

Figura 2 - Aspectos do lodo e do solo.

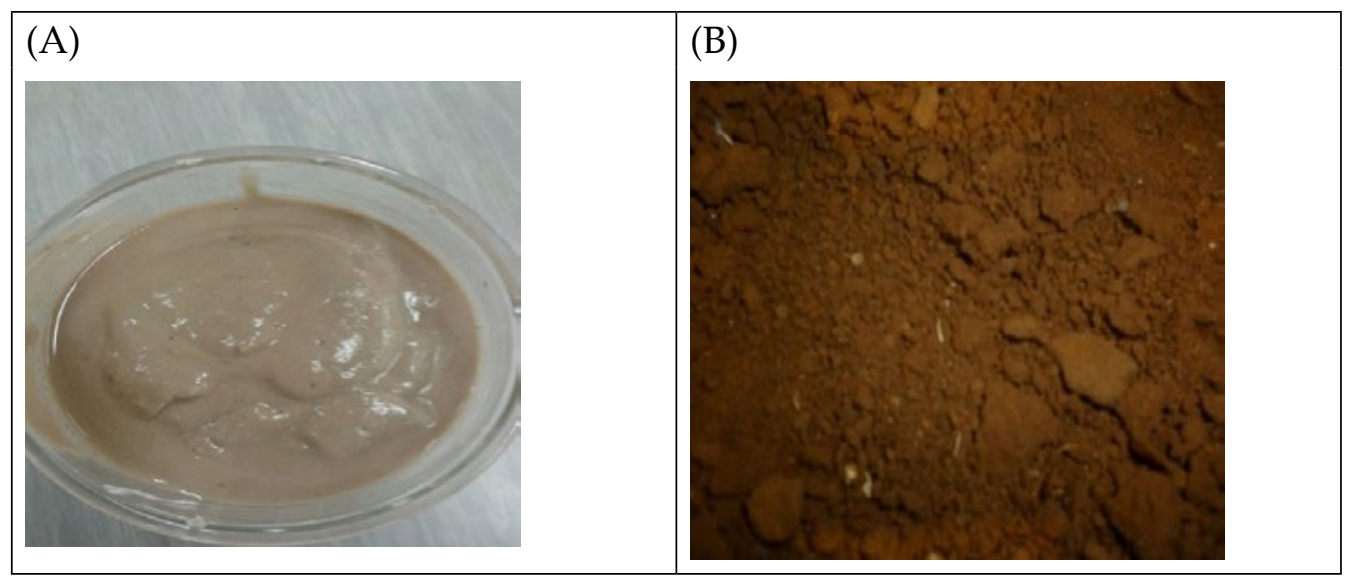

Fonte: Dos autores.

\subsection{Teste de fuga}

O teste teve como principal objetivo expor as minhocas simultaneamente às amostras de resíduos do efluente de curtume (seco) e solo úmido, avaliando o comportamento de fuga das minhocas. $\mathrm{O}$ teste de fuga foi realizado de acordo a norma da Internacional Organization for Standardization (ISO -TC/190/SC 4/ WG $2 \mathrm{n}^{\circ} 153$ de 2003). Para este teste, foram realizadas as misturas de acordo com o Quadro 1 . O teste teve duração de $48 \mathrm{~h}$ e foi mantida a temperatura de 20 $\pm 2{ }^{\circ} \mathrm{C}$. 
Quadro 1 - Misturas realizadas no teste de fuga

\begin{tabular}{|l|l|}
\hline Teste & Mistura \\
\hline Teste 1 & $60 \%$ resíduo: $40 \%$ solo \\
\hline Teste 2 & $50 \%$ resíduo: $50 \%$ solo \\
\hline Teste 3 & $40 \%$ resíduo: $60 \%$ solo \\
\hline Teste 4 & $30 \%$ resíduo: $70 \%$ solo \\
\hline Teste 5 & $20 \%$ resíduo: $80 \%$ solo \\
\hline Teste 6 & $10 \%$ resíduo: $90 \%$ solo \\
\hline
\end{tabular}

Fonte: Dos autores.

Após verificar a melhor proporção de resíduo e solo, foram feitos três minhocários para o processo de vermicompostagem e mais três minhocários, na mesma proporção, considerados "branco", usando apenas o solo e o resíduo (sem as minhocas). Este processo permaneceu em um período de 60 dias para a degradação do material orgânico e transformação em húmus.

\subsection{Montagem do branco e da vermicompostagem}

Após o teste de fuga, foram montados seis minhocários na horizontal em recipientes retangulares de plástico nas dimensões $10 \mathrm{~cm} \times 10 \mathrm{~cm} \times 17 \mathrm{~cm}$. Para o grupo controle, foram montados os potes, sendo adicionado apenas solo e a proporção da mistura de resíduo e solo. Para a montagem dos minhocários (FIGURA 3), foram feitos os mesmos procedimentos, e adicionadas 15 minhocas da espécie Ensenia andrei. Os recipientes foram identificados e cobertos com tampa perfurada para evitar fugas e proteger contra predadores, temperatura e umidade.

Figura 3 - Minhocários da vermicompostagem

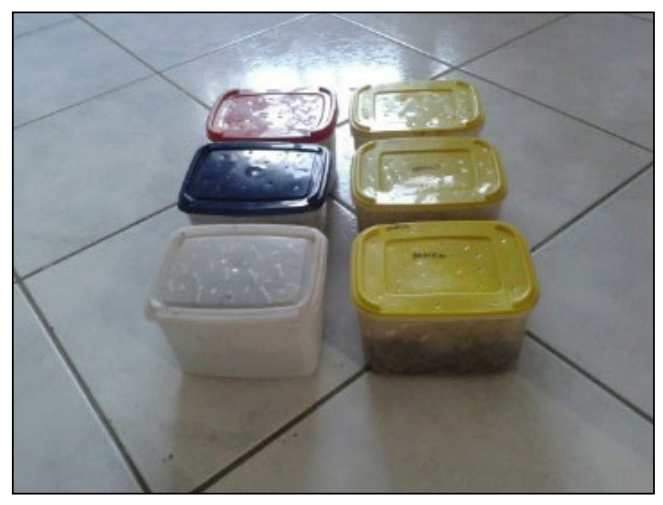

Fonte: Dos autores 
Após obter o vermicomposto (60 dias), plântulas de rúcula - (Feltrin) foram plantadas em diferentes proporções de húmus (contendo o resíduo de curtume na proporção definida pelo teste de fuga). Para controle do efeito do húmus sobre o cultivo das rúculas, as plântulas também foram plantadas em substratos contendo o branco e solo. Assim, obtiveram-se nove tratamentos, conforme se pode observar no Quadro 2.

Quadro 2 - Tratamentos utilizados para o cultivo das plântulas

\begin{tabular}{|l|l|}
\hline Tratamento & Composição do substrato \\
\hline T1 & $100 \%$ de solo \\
\hline T2 & $25 \%$ de húmus : $75 \%$ de solo \\
\hline T3 & $50 \%$ de húmus $: 50 \%$ de solo \\
\hline T4 & $75 \%$ de húmus : $25 \%$ de solo \\
\hline T5 & $100 \%$ de húmus \\
\hline T6 & $25 \%$ de branco: $75 \%$ de solo \\
\hline T7 & $50 \%$ de branco: $50 \%$ de solo \\
\hline T8 & $75 \%$ de branco: $25 \%$ de solo \\
\hline T9 & $100 \%$ de branco \\
\hline
\end{tabular}

Fonte: Dos autores

Cabe salientar que tanto os testes contendo o húmus quanto os testes contendo o "branco" apresentam a mesma mistura de resíduo definido pelo teste de fuga. Esses testes foram baseados em Stevens (2014), a qual usou a vermicompostagem para a redução de $\mathrm{Cr}$ do lodo de curtume. Após aplicação como fertilizante em cultivo de cebolinha e uso destas proporções para verificar qual a melhor proporção de mistura que as minhocas se adaptassem.

\subsection{Crescimento das plantas}

Foram plantadas 18 plântulas de rúcula em bandejas de isopor. As mesmas foram cultivadas em estufa com temperatura e umidade controladas por 50 dias nas casas de vegetação da Univates. As plantas foram molhadas diariamente com água destilada.

\subsection{Variáveis avaliadas}

A caracterização do solo e do húmus foram feitas usando análises de $\mathrm{N}, \mathrm{P}, \mathrm{K}, \mathrm{pH}$ conforme os seguintes procedimentos: $\mathrm{pH}$ (APHA/AWWA, $22^{\mathrm{a}}$ ed. 2530), nitrogênio Kjeldahl (EMBRAPA, 2011/STANDARD METHODS, $22^{a}$ ed. 4500F), fósforo (Digestão 4500-P (E) e potássio e cromo (MA 070/L2). Os ensaios foram realizados pelo laboratório INNOLAB do Brasil Ltda (laboratório 
de ensaio acreditado pela CGCRE/ INMETRO, de acordo com a ABNT NBR ISSO/IEC 17025).

Para a análise de cromo total e sua especiação, amostras de solo e de húmus foram enviadas para um laboratório terceirizado, conforme os seguintes procedimentos: Cromo III (APHA/AWWA, 22 ed., 3030F/3120B e 3500-Cr B) e Cromo IV (EPA 3060 e 3500 Cr B).

Para verificar o crescimento das rúculas após o período de 50 dias em estufa, as plantas foram submetidas às análises de massa fresca, massa seca, altura total, comprimento da raiz e o número de folhas, conforme Favelessa, (2011) e Stevens (2014). Estes resultados foram submetidos à análise estatística (Teste de Tukey - P $<0.05$ - Programa Infostat).

\section{RESULTADOS E DISCUSSÕES}

Inicialmente, o teste da fuga mostrou que as minhocas se adaptaram na proporção de $10 \%$ de resíduo seco e $90 \%$ de solo. Cabe salientar que com a secagem do resíduo, houve redução de 16 vezes o volume inicial. Os resultados da caracterização do solo usado neste trabalho, bem como do lodo de curtume, estão descritos na Tabela 1.

Tabela 1 - Caracterização do solo da região do Vale do Taquari (argissolo) e do lodo de curtume da indústria de curtimento

\begin{tabular}{l|c|c}
\hline Parâmetro & Solo & $\begin{array}{c}\text { Lodo de curtume (pó } \\
\text { concentrado) }\end{array}$ \\
\hline Cromo total $\left({\left.\mathrm{mg} \cdot \mathrm{Kg}^{-1}\right)}^{-1}\right.$ & 21 & 1070 \\
\hline Cromo III $\left(\mathrm{mg} \cdot \mathrm{Kg}^{-1}\right)$ & 21 & 1070 \\
\hline Cromo IV $\left(\mathrm{mg} \cdot \mathrm{Kg}^{-1}\right)$ & $\mathrm{Nd}$ & $\mathrm{Nd}$ \\
\hline $\mathrm{pH}$ & 5,22 & 8,53 \\
\hline
\end{tabular}

Fonte: Dos autores

Como pode ser visto, havia alta concentração de Cr III no lodo. Por mais que essa especiação não é tóxica, deve ser tratado em função de ser um metal e estar contido no resíduo em alta concentração. Além disso, conforme a Resolução 375 da CONAMA (2006), o limite do cromo total para destinação em solo agrícola é de $1000 \mathrm{mg} \cdot \mathrm{kg}^{-1}$ na base seca. Dessa forma, inicialmente, o lodo de curtume (pó concentrado) estava incapacitado de ser aplicado como biofertilizante em solo agrícola. Após 60 dias de decomposição do resíduo (branco) e de processo de vermicompostagem, foram feitas as análises de $\mathrm{Cr}, \mathrm{N}$, $\mathrm{P}, \mathrm{K}$ e pH. Os resultados estão descritos na Tabela 2. 
Tabela 2 - Caracterização do branco e da vermicompostagem antes e após os 60 dias de decomposição do resíduo

\begin{tabular}{|c|c|c|c|}
\hline Parâmetro & $\begin{array}{l}\text { Branco } \\
\text { inicial }\end{array}$ & $\begin{array}{c}\text { Branco } \\
\text { após } 60 \text { dias }\end{array}$ & $\begin{array}{l}\text { Vermicompostagem } \\
\text { após } 60 \text { dias }\end{array}$ \\
\hline Cromo total (mg. Kg $\left.{ }^{-1}\right)$ & 128 & 119 & 97 \\
\hline Cromo III (mg.Kg-1) & 128 & 119 & 97 \\
\hline Cromo IV (mg.Kg $\left.{ }^{-1}\right)$ & $<\mathrm{LD}$ & $<\mathrm{LD}$ & $<\mathrm{LD}$ \\
\hline Nitrogênio K(mg. $\left.\mathrm{Kg}^{-1}\right)$ & 0,1616 & $0,36 \pm 0,08$ & $0,46 \pm 0,06$ \\
\hline Potássio $\left(\mathrm{mg} \cdot \mathrm{Kg}^{-1}\right)$ & 0,2057 & $0,6770 \pm 0,005$ & $0,835 \pm 0,06$ \\
\hline Fósforo (mg. Kg-1 $)$ & 0,1771 & $0,7247 \pm 0,02$ & $0,7603 \pm 0,02$ \\
\hline $\mathrm{pH}$ & 8,00 & 7,84 & 6,90 \\
\hline
\end{tabular}

$<$ LD: limite de detecção da técnica.

Fonte: Dos autores

Observando os resultados da Tabela 2, foi possível verificar a redução dos teores de $\mathrm{Cr}$ tanto no branco após 60 dias, quanto na vermicompostagem, sendo mais pronunciada a redução neste último processo (redução de $23 \%$ do $\mathrm{Cr}$ original). Pode-se observar que não houve transformação de $\mathrm{Cr}$ III para VI, não sendo tóxico e estando em concentrações bem abaixo do limite permitido pela legislação. Houve maior acréscimo de N, K e P na vermicompostagem do que no branco.

Estes resultados vão ao encontro com o trabalho do autor Shipitalo \& Bayon (2004), pois segundo o estudo, quando o resíduo é passado pela digestão das minhocas, o solo é misturado com muco digestivo, o qual ajuda na união de partículas, e na deposição fecal, que contém grandes concentrações de nutrientes que ajuda no desenvolvimento do húmus e na fertilidade do solo. Os valores de $\mathrm{pH}$ reduziram provavelmente devido à formação de ácidos húmicos e fúlvicos, próprios da decomposição de resíduos orgânicos.

Cotta et al. (2015) compararam técnicas na compostagem e vermicompostagem utilizando resíduos vegetais, esterco bovino e serragem. Os autores perceberam uma diminuição do $\mathrm{pH}$ em todos os tratamentos utilizando diferentes resíduos.

Albanell et al. (2008) e Haimi et al. (1986) atribuem a diminuição do $\mathrm{pH}$ em relação à produção de $\mathrm{CO}_{2}$ e ácidos orgânicos presentes no processo de vermicompostagem. Assim, pode-se verificar que o processo de vermicompostagem contribuiu para um aumento nos nutrientes no substrato.

De acordo com os resultados de massa fresca e seca nas plantas, podese observar que não houve diferença estatística entre o T1 (sem húmus e sem resíduo) e todos os testes usando o húmus (GRÁfICO 1). Porém, no teste T8 ( $75 \%$ de branco: $25 \%$ de solo) há diferença significativa, ou seja, nessa proporção, 
houve redução da massa fresca e seca. Esses resultados indicam que o resíduo influencia nesses dois parâmetros quando em maiores proporções e sem o uso de húmus.

Gráfico 1 - Massa fresca e massa seca das plantas de rúcula

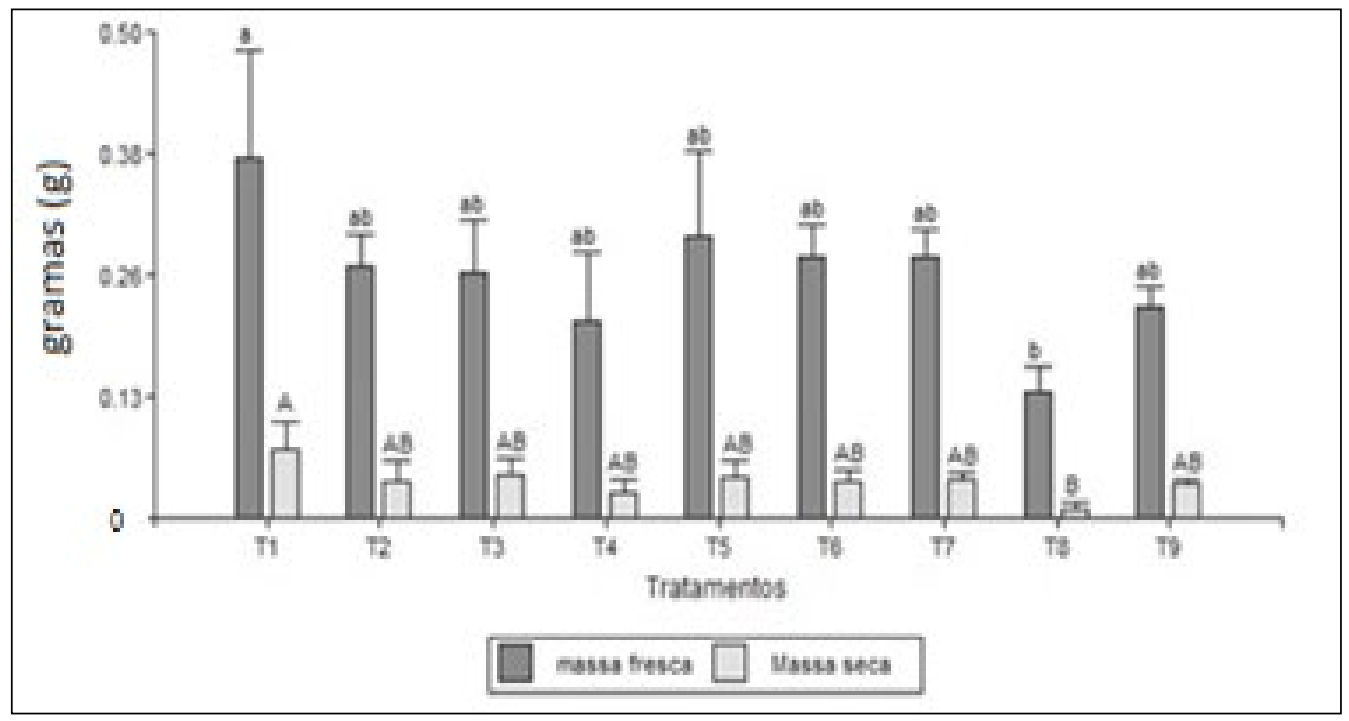

Fonte: Dos autores

No parâmetro altura, o resíduo influenciou negativamente no crescimento da parte aérea da planta. No entanto, na amostra de menor altura (T8) foi usado somente solo (contendo resíduo) e o branco. Conforme Ensinas et al. (2011), considerando a altura das mudas de rúcula com diferentes combinações de substratos, o tratamento que utilizou apenas substrato (T1) foi o que apresentou a maior altura $(81,4 \mathrm{~mm})$, diferindo dos demais tratamentos. 
Gráfico 2 - Altura total das plantas

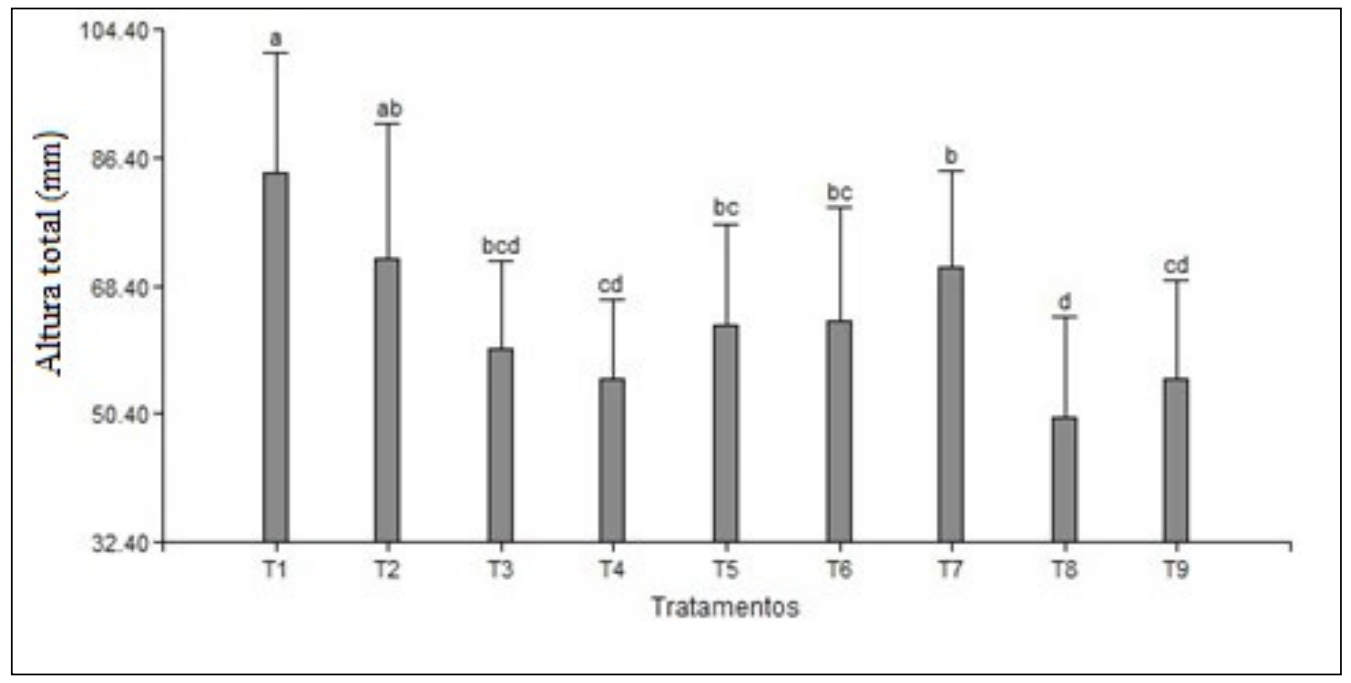

Fonte: Dos autores

Pôde-se verificar que nos tratamentos que possuem baixa proporção de resíduo (T2, T6 e T7), não houve diferença estatística em relação ao T1 (sem resíduo). Conforme foi aumentando a concentração de resíduo, houve redução do comprimento da raiz, prejudicando a sustentação da planta. Evidenciouse, ainda, a diferença estatística a partir de T8 em relação aos demais testes, ou seja, usando maiores teores de branco sem húmus. Assim, uma proporção de $25 \%$ de húmus e $75 \%$ de solo pode auxiliar no desenvolvimento da raiz em meios contendo resíduos de curtume. 
Gráfico 3 - Comprimento da raiz das plantas

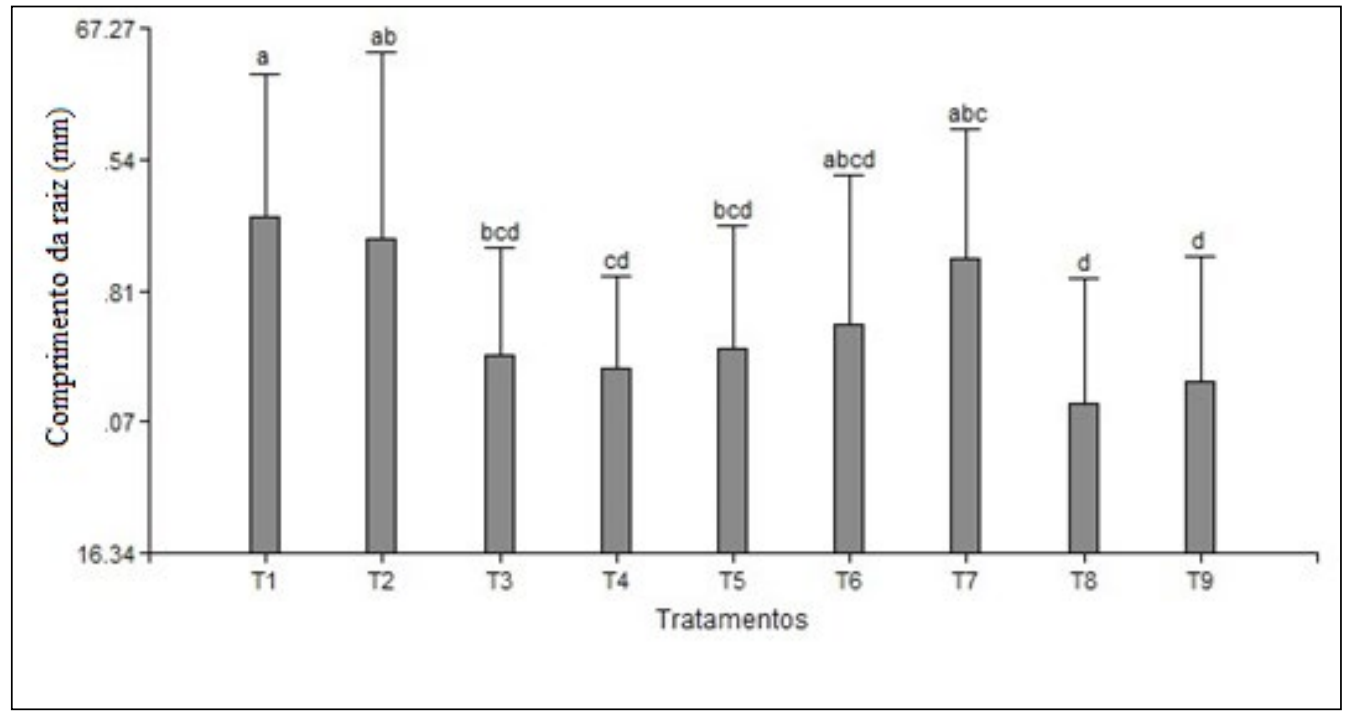

Fonte: Dos autores

O número de folhas é um parâmetro muito suscetível a outros fatores externos, como ataque por formigas e exposição à luz. Em T5 (100\% húmus) mostra uma diferença estatística grande, pois neste tratamento houve mais plantas mortas do que nos demais tratamentos e, consequentemente, acarretou em menos folhas. De acordo com os resultados de Stevens (2014) em relação ao número de folhas, nenhum dos tratamentos diferiu, considerando os tratamentos entre as diferentes espécies de minhocas. Porém, os tratamentos com as maiores concentrações de húmus mostram que a quantidade de folhas diminuiu na medida em que aumentou a concentração de húmus. 
Gráfico 4 - Número de folhas das plantas

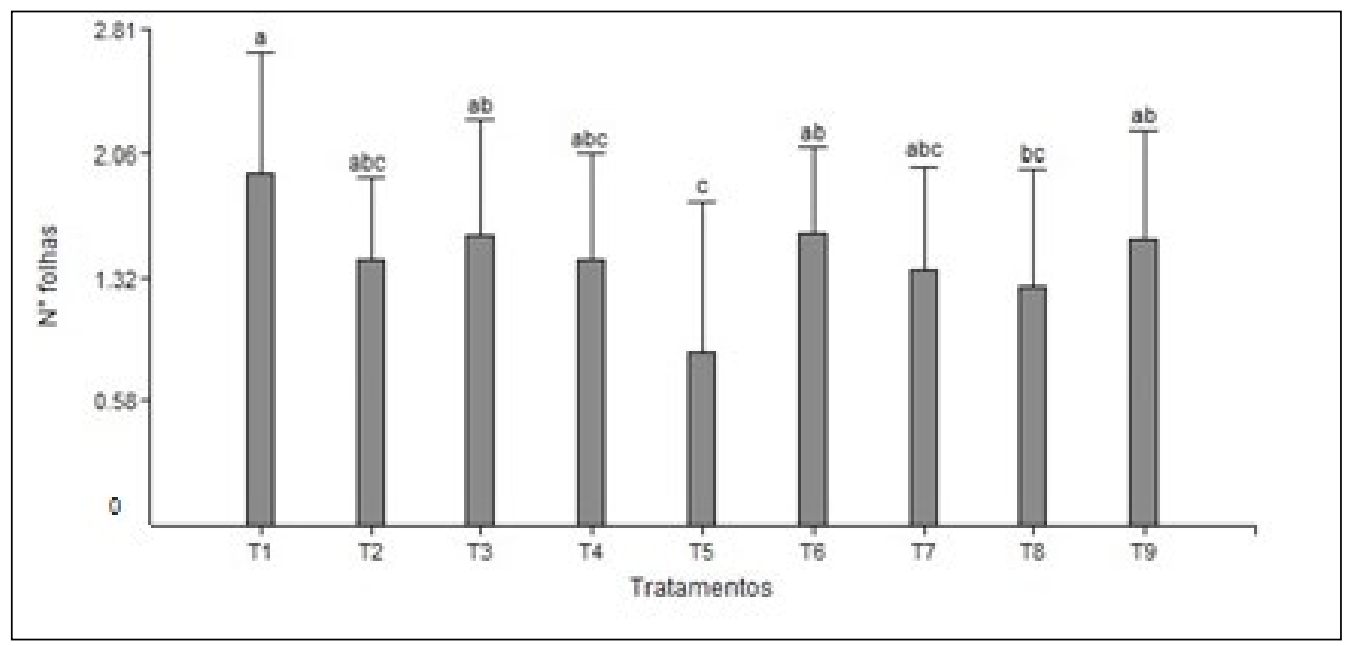

Fonte: Dos autores

Alguns estudos foram realizados com resíduo de curtume e posterior aplicação em plantações. Araújo et al. (2008) analisaram o acúmulo de nutrientes no milho e concluíram que as plantas cultivadas em solo com lodo de curtume obtiveram aumento significativo dos parâmetros fósforo e nitrogênio quando comparados com tratamentos sem este resíduo. Quanto às análises de $\mathrm{Cr}$ no milho, estas não foram realizadas.

Kray et al. (2008) pesquisaram sobre a aplicação de resíduos de curtume sobre plantas de milho e soja plantadas em um solo vermelho. Os resultados obtidos foram positivos indicando que o lodo de curtume pode contribuir para a neutralização da acidez do solo e pode adquirir uma boa fonte de nitrogênio para as plantas.

Costa et al. (2011) avaliaram a vermicompostagem de resíduos de efluentes de frigorífico aplicando diferentes proporções desse efluente com casca de arroz. Após, o biofertilizante foi usando em plantação de alface. Obtiveram aumento de $40 \%$ de crescimento das plantas.

Shukla et al. (2011) constataram a redução de 70\% do metal cromo em plantações de Eucalyptus tereticornis em depósitos de lodo de curtume após um ano de estudos.

\section{CONCLUSÃO}

Foi possível aplicar o processo da vermicompostagem para aproveitar o lodo oriundo do resíduo sólido de curtume.

O húmus gerado apresentou mais teores de N, P e K do que em relação ao solo original. Também, com o processo da vermicompostagem, houve 
reduções significativas dos teores de $\mathrm{Cr}$, deixando o solo com o limite de tolerância abaixo do que a legislação permite.

Quanto ao uso de húmus em plantações de rúcula, este contribuiu para o crescimento da planta, podendo ser usado nas proporções de $25 \%$ de húmus e $75 \%$ de solo, sem apresentar diferença estatística em relação ao T1 (teste sem resíduo) na massa fresca e seca, no crescimento da parte aérea, na raiz e no número de folhas. $\mathrm{O}$ resíduo influenciou negativamente no crescimento da raiz, o que pode prejudicar na sustentação e na aquisição de minerais da planta do solo.

Assim, testes posteriores para avaliar a concentração de $\mathrm{Cr}$ nos vegetais ainda serão feitos, para avaliar o efeito de absorção deste metal com e sem o uso do húmus como fertilizante. Este trabalho pode contribuir para pesquisas posteriores que desenvolvem métodos para reaproveitar resíduos de curtume.

\section{REFERÊNCIAS}

ASSOCIAÇÃO BRASILEIRA DE NORMAS TÉCNICAS (ABNT). NBR 13591: 1996. Compostagem. Rio de Janeiro: ABNT, 1996.

ALBANELL, Elena; PLAIZATS, Josefina; CABRERO, T. Chemical changes during vermicomposting (Eisenia fetida) of sheep manure mixed with cotton industrial wastes. Biology and Fertility of Soils. v. 6, p. 266-269, 1988. DOI: 10.1007/BF00260823

ALCÂNTARA, Marcos A. K; CAMARGO, Otávio A. Transporte de crômio trivalente influenciado pelo $\mathrm{pH}$, horizonte do solo e fontes do crômio. Revista Brasileira de Engenharia Agrícola e Ambiental. v. 5, n. 3, 2001. Disponível em: < http://dx.doi. org/10.1590/S1415-43662001000300022>. Acesso em: 04 dez. 2017.

APHA - American Public Health Association; AWWA - American Water Works Association; WEF - Water Environment Federation. Standard Methods for the Examination of Water and Wastewater. 22. ed. Washington - DC: APHA, 2015.

ARAÚJO, Fabio F. de; GIL, Fábio.C.; TIRITAN, Carlos S. Lodo de esgoto na fertilidade do solo, nutrição de Brachiaria decumbens e na atividade de desidrogenase. Pesquisa Agropecuária Tropical. v. 39, n. 1, p. 1-6, 2009. Disponível em: <https://www. revistas.ufg.br/pat/article/view/3319/4461>. Acesso em: 04 dez. 2017.

ARAÚJO, Fabio F. de; JÚNIOR, O. C; PERREIRA, Helder M; TIRITAN, Carlos S. Desenvolvimento do milho e fertilidade do solo após aplicação de lodo de curtume e fosforita. Revista Brasileira de Engenharia Agrícola e Ambiental. v. 12, n.5, p. 507511, 2008. Disponível em: < http://dx.doi.org/10.1590/S1415-43662001000300022>. Acesso em: 04 dez. 2017. DOI: 10.1590/S1415-43662008000500011

BUTT, Kevin R. Utilization of soil paper-mill sludge and spend brewery yeast as a feed for soil-dwelling earthworms. Bioresource Technology. v. 44, p. 105-107, 1993. 
Disponível em: <https://doi.org/10.1016/0960-8524(93)90182-B>. Acesso em: 05 mar. 2016. DOI: $10.1016 / 0960-8524(93) 90182-B$

CAMPOS, José R. Tratamento de esgotos sanitários por processo anaeróbio e disposição controlada do solo. Rio de Janeiro, 1999. Disponível em: <http:/ /base. repositorio.unesp.br/bitstream/handle/11449/111149/000797267.pdf?sequence $=>$. Acesso em: 10 de Ago. de 2016.

CASTILHOS, Danilo D. Alterações químicas e biológicas devidas à adição de resíduos de curtume e de cromo hexavalente ao solo. Tese (Doutorado em Ciência do Solo) - Faculdade de Agronomia, Universidade Federal do Rio Grande do Sul, Porto Alegre, 1998.

CASTILHOS, Danilo D.; COSTA, Claudia N.; PASSIANOTO, Caio C.; DE LIMA, Ana C. R; DE LIMA, Claudia L; MULLER, Valberto. Adição de cromo hexavalente no crescimento, nodulação e absorção de nutrientes em soja. Ciência Rural. Santa Maria, v. 31, n. 6, p. 969-972, 2001. Disponível em: <http:/ / revistas.bvs-vet.org.br/crural/ article/view/15567/16433>. Acesso em: 10 ago. 2016. ISSN 0103-8478

CLASS, Isabel C; MAIA, Roberto A. Manual básico de resíduos industriais de curtume. Porto Alegre. SENAI/RS, 1994.

CONSELHO ESTADUAL DO MEIO AMBIENTE (CONSEMA). Resolução n ${ }^{\circ}$ 128, de 24 de novembro de 2006. Fixação de Padrões de Emissão de Efluentes Líquidos para fontes de emissão que lancem seus efluentes em águas superficiais no Estado do Rio Grande do Sul. Diário Oficial da república federativa do Brasil, Brasília, DF, 24 de novembro de 2006. Disponível em: http:/ / www.bioensaios.com.br/legisla/ FEPAM\%20CONSEMA128\%20Efluentes.pdf > . Acesso em: 05 nov. 2017.

CONSELHO NACIONAL DO MEIO AMBIENTE (CONAMA). Resolução n ${ }^{\circ}$ 357, de 17 de março de 2005. Condições e padrões de lançamento de efluentes. Diário Oficial da república federativa do Brasil, Brasília, DF, 16 de maio de 2011. Disponível em: < http:/ / www.mma.gov.br/port/conama/legiabre.cfm?codlegi=459>. Acesso em: 05 nov. 2011.

COTTA, J. A. de O; CARVALHO, N. L. C.; BRUM, T. da S; REZENDE, M. O. de O. Compostagem versus vermicompostagem: comparação das técnicas utilizando resíduos vegetais, esterco bovino e serragem. Eng Sanit Ambient. v.20, n.1, p. 6578, jan/mar 2015. Disponível em: <http:/ / www.scielo.br/pdf/esa/v20n1/14134152-esa-20-01-00065.pdf>. Acesso em: 16 ago. 2017. DOI: 10.1590/S141341522015020000111864

COSTA, Manuela; MIRANDA, Fernando; VELOSO, Abel. A vermicompostagem como via para a reciclagem de nutrientes na exploração agrícola: efeitos na produção da alface em MPB. COLOQUIO NACIONAL DE HORTICULTURA BIOLÓGICA, 3, 2011, Braga. Atas... Disponível em: <http:/ / www.drapn.min-agricultura.pt/drapn/ conteudos/laboratorio/Vermicomp-rev.pdf>. Acesso em: 01 out. 2017. 
FAVALESSA, Marcilene. Substratos renováveis e não renováveis na produção de mudas de acacia mangium. Monografia (Mestrado) - Departamento de Engenharia Florestal, Universidade Federal do Espírito Santo, Jerônimo Monteiro, 10 nov. 2011. Disponível em: <http:/ / www.florestaemadeira.ufes.br/sites/florestaemadeira.ufes. br/files/TCC_Marcilene\%20Favalessa.pdf>. Acesso em: 29 nov. 2017

GARG, V. K.; YADAY, A. Vermicomposting: An effective tool for the management of invasive weed Parthenium hysterophorus. Bioresour Technology. v. 102, n. 10, p. 58915895, 2011. Disponível em: <https://doi.org/10.1016/j.biortech.2011.02.062>. Acesso em: 14 abr. 2014. DOI: 10.1016/j.biortech.2011.02.062

HAROUN, Mahdi; IDRIS, Azni; OMAR, Syed. Analysis of heavy metals during composting of the tannery sludge using physicochemical and spectroscopic techniques. Journal of Hazardous Materiais. v. 165, p. 111-119, 2009. Disponível em: <https:/ / doi.org/10.1016/j.jhazmat.2008.09.092>. Acesso em: 04 dez. 2017. DOI: 10.1016/j.jhazmat.2008.09.092

ISO - International Organization for Standardization. Avoidance Test for Testing the Qualy of Soils and the Toxicity of Chemicals: test with eartworms. Desiganation: ISO/TC 190/SC 4N 0238 DRAFT, 2003.

KRAY, Cláudio H. Efeitos da aplicação e da reaplicação de resíduos carboníferos e de curtume no solo e nas plantas. Dissertação (Mestrado em Ciências do Solo) Universidade Federal do Rio Grande do Sul, Porto Alegre, 2001.

KRAY, Cláudio H.; TEDESCO, Marino J.; BISSANI, Carlos A; GIANELLO, Clesio ; SILVA, Kelly J. Tannery and coal mining waste disposal on soil. Revista Brasileira de Ciência do Solo. v. 32, p. 2877-2882, 2008. Disponível em: <http:/ /dx.doi. org/10.1590/S0100-06832008000700035>. Acesso em: 6 mai. 2017. DOI: 10.1590/S010006832008000700035

KONRAD, E.E.; CASTILHOS, D.D. Alterações químicas do solo e crescimento do milho decorrente da adição do lodo de curtume. Revista Brasileira de Ciência do Solo. v. 26, p. 257-265, 2002. Disponível em: <http:/ /dx.doi.org/10.1590/ S0100-06832002000100027>. Acesso em: 15 de ago. 2014. DOI: 10.1590/S010006832002000100027

MARCONDES, Ayrton C.; LAMMOGLIA, Domingos A. Biologia: ciência da vida. São Paulo: Atual, 1994.

SCHIRMER, Guilherme K. Utilização do lodo de esgoto na Vermicompostagem e como substrato para a produção de mudas de pinus (Elliottiiengelm). Dissertação (Mestrado em Ciências do Solo) - Universidade Federal de Santa Maria, 2010.

SHUKLA, O. P.; JUWARKAR, A. A.; SINGH, S. K.; KHAN, S.; RAI, U. N. Growth responses and metal accumulation capabilities of woody plants during the phytoremediation of tannery sludge. Waste Management. v. 31, n. 1, p. 115-123, 2011. Disponível em: <https://doi.org/10.1016/j.wasman.2010.08.022 >. Acesso em: 20 de out. 2017. DOI: 10.1016/j.wasman.2010.08.022. 
SHIPITALO, Martin J.; BAYON, Renée-C. Le. 2004. Quantifying the effects of earthworms on soil aggregation and porosity. Pp. 183-200. In: C.A. Edwards (Ed.). Earthworm ecology. 2 nd Ed.CRC Press, Boca Raton.

STEVENS, Débora. O uso da vermicompostagem para redução do cromo em lodo de curtume e após aplicação como fertilizante em cultivo de cebolinha (Allium fistulosum 1.). Dissertação (Mestrado) - Curso de Biotecnologia, Centro Universitário UNIVATES, Lajeado, 12 dez. 2014. Disponível em: < http:/ / hdl.handle. net $/ 10737 / 720>$.

STOMBERG, A. L.; HEMPHILL, D. D.; VOLK, V. V. Yield and elemental concentration of sweet corn grown on tannery waste-amended soil. Journal of Environmental Quality. Madison. v. 13, p. 162-166, 1983. Disponível em: <https:/ / dl.sciencesocieties. org/publications/jeq/abstracts /13/1/JEQ0130010162 access $=0 \& v i e w=p d f ~>$. Acesso em: 10 de nov. 2017. DOI: 10.2134/jeq1984.00472425001300010030x

TEDESCO, Marino J.; GIANELLO, Clesio; BISSANI, C. A.; BOHNEN, Humberto; VOLKWEISS, Sérgio J. Análise de solo, plantas e outros materiais. 2. ed. Universidade Federal do Rio Grande do Sul, Porto Alegre, 1995.

TEGNER, J. Gestão de Tratamento de Resíduos de Curtume. Estância Velha: SENAI, p. 55, 2004.

TEIXEIRA, Jose A. O. S. Descarte de resíduo de curtume no solo. Dissertação (Mestrado em Ciência do Solo) - Faculdade de Agronomia, Universidade Federal do Rio Grande do Sul, Porto Alegre, 1981. 